College of Salerno brought to the West a system of professional medical practice which has since prevailed in all parts of the civilized world.

\section{A New Kind of Museum Exhibit}

THE New England Museum of Natural History in Boston, Mass., has been the first to turn a trade innovation in lighting to the service of museum galleries. In the particular case described by Bradford Washburn in the Museums Journal $(39,450 ; 1940)$ you gaze at a stoat watching you from the edge of a summer wood. As you look, the lights fade, become momentarily dim, and when the full light shows again the summer scene has gone, snow covers the ground, the trees are bare of leaves, and the stoats have changed into their winter dress of ermine. The case really contains two groups, a summer and a winter one ; but the spectator looking at the summer group perceives it, when it is brilliantly lit internally, through a transparent sheet of Belgian 'black' glass. When the internal lights fade and the second group is illuminated, the black glass becomes opaque and acts as a mirror in which only the snow scene is visible, exactly overlapping the summer scene, of which it is a replica in reverse. Many technical difficulties had to be surmounted before the new exhibit was satisfactorily completed ; but its dissolving habitat group at once made a great impression. One wonders if the average mortal really needs such bait in order to be induced to look at a representation of Nature: and the result--half his mind is thinking about the trick of the thing; only the other half is giving itself to the study of the Nature group.

\section{Earthquakes Near Great Dams}

According to Earthquake Notes (11, No. 3; January 1940), earthquakes of varying intensity have been recorded from the neighbourhood of Boulder Dam since September 1936. During the first four months twelve shocks were felt, but the frequency increased until during A.pril 1937 forty-five were felt. After this time the frequency increased until during the early part of 1939 there were on average two humanly felt earthquakes a month. The Wood-Anderson seismograph on the spot recorded more than five hundred disturbances during 1938. There has been some discussion among U.S. seismologists of plans for the observation of possible earthquakes in the neighbourhood of two other areas which will probably be similarly loaded. The first is the unfinished Grand Coulee Dam in the State of Washington, and the second is the proposed Shasta Dam near the confluence of the Pit and Sacramento Rivers in northern California. In the latter case there is yet time to obtain information of the seismicity of the area before loading. Similar data were not obtained in the case of the Boulder Dam.

\section{Oxygen Administration and Inhalation Apparatus}

A FIFTH memorandum in the Emergency Medical Services Series has been issued by the Ministry of Health entitled "Oxygen Administration-Indica- tions, Methods and Types of Apparatus" (H.M. Stationery Office. 2d. net). The administration of oxygen is a valuable aid in the treatment of some forms of gas poisoning and lung disease, and in some surgical conditions such as shock and chest wounds. The memorandum incorporates the results of research on the subject, and is intended primarily for the guidance of medical officers in charge of hospitals. It describes the conditions for which oxygen therapy is likely to be effective, methods of oxygen administration, and the more important types of apparatus for the purpose, including a new form of nasal mask.

\section{Alexander Pedler Lecture}

The Alexander Pedler Lecture, which is given annually under the auspices of the British Association, was this year delivered by Prof. Allan Ferguson before the Cardiff Naturalists' Society. The lecture, which was given in the Reardon Smith Lecture Theatre of the National Museum of Wales, Cardiff, on March 14, was entitled "Splashes, and what they Teach". It was chiefly concerned with an explanation of the phenomena attendant on the impact of a drop of liquid on a liquid or solid surface. A high-speed film was shown which illustrated the phenomena, and the results were compared with those of the earlier classical experiments carried out by the late Prof. Worthington.

\section{Old Books on Social Sciences}

WE have received a copy of Catalogue 54 published by E. P. Goldschmidt and Co., of 45 Old Bond Street, W.1, containing 307 items of old works dealing with a great variety of subjects. Attention may be directed to the following: Jacques Legrand's "Sophologium", a popular handbook of useful knowledge, possibly printed by Caxton, not later than 1473; Naudé's work on the principles of librarianship and library organization (1627); Beccaria's treatise on crimes and penalties (1766); Sir Edwin Chadwick's "Report on the Sanitary Condition of the Labouring Population of Great Britain" (1842) ; Patissier's work on factory hygiene and the diseases to which miners, industrial workers and others are exposed (1822); Schreiber's sixteenth century book on practical arithmetic, the first German book on the subject; Jérome de Monteux's treatise on hygiene, which contains chapters on dietetics, the care and nourishment of children, and a section on cosmetics (1559); Bernard Palissy's discourse on the nature of waters, fountains, rains, metals, salts, stones, earths and fire (1580), which entitles him to be regarded as one of the pioneers of modern chemistry and geology; Neander's "Tabacologia" (1626), the most important early work on tobacco ; Villafranca's "Methodus refrigerandi" (1550), the earliest work on artificial refrigeration; and the first edition of Linnæus's book on the increase of the habitable earth (1744) bound up with the second edition of his oration on travelling in one's own country (1743). 